\title{
Penerapan Metode Hungarian Dalam Penugasan Dosen Pengampu Mata Kuliah Program Studi Matematika FMIPA Universitas Mataram
}

\section{Muhammad Khairurradziqin ${ }^{a}$, Ahmad Tedi Ruslan ${ }^{b}$, Dzakiyatul Mardliyah ${ }^{c}$, Fahmi Handika ${ }^{\text {, }}$ Mamika Ujianita Romdhini e* $^{*}$}

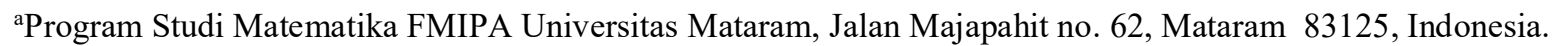
Email:radziq@cileungsi.com

bProgram Studi Matematika FMIPA Universitas Mataram, Jalan Majapahit no. 62, Mataram 83125, Indonesia. Email:ahmadtediruslan@gmail.com

'Program Studi Matematika FMIPA Universitas Mataram, Jalan Majapahit no. 62, Mataram 83125, Indonesia. Email:dzakiyatul.mardliyah@gmail.com

dProgram Studi Matematika FMIPA Universitas Mataram, Jalan Majapahit no. 62, Mataram 83125, Indonesia. Email:fahmihandika@gmail.com

eProgram Studi Matematika FMIPA Universitas Mataram, Jalan Majapahit no. 62, Mataram 83125, Indonesia.

Email:mamika.ur@yahoo.com

\section{A B S T R A C T}

The tight schedule of lecture activities requires accuracy so that it always runs smoothly. Lecturer assignments play an important role to ensure the smooth lecture activities. Problems that often occur in the assignment of these lecturers need to be avoided. In an effort to reduce the risk of problems that occur in the assignment of lecturers, it is necessary to make a structured system with the right method. Hungarian method can be said very appropriate for this assignment problem because each course will only be charged to one lecturer. Another advantage of using the hungarian method in this lecturer assignment model is also because it uses the preferences of prospective lecturers as subjects of measurement. Each lecturer will take courses according to their best preferences with the expectation that the lecturer will have more mastery in the courses that he will teach.

Keywords: Lecturer, Assignment Problem, Course, Hungarian Method, preferences

* Corresponding author.

Alamat e-mail: mamika.ur@yahoo.com 
A B S T R A K

Padatnya jadwal pada kegiatan perkuliahan memerlukan ketepatan agar selalu berjalan dengan lancar. Penugasan dosen memegang peran penting untuk menjamin lancarnya kegiatan perkuliahan tersebut. Permasalahan yang kerap terjadi dalam penugasan dosen ini perlu dihindari agar tidak menghambat lancarnya kegiatan perkuliahan. Sebagai usaha mengurangi resiko permasalahan yang terjadi dalam penugasan dosen tersebut, perlu dibuatkan sistem terstruktur dengan metode yang tepat. Metode hungarian dapat dikatakan sangat tepat untuk model penugasan ini dikarenakan setiap mata kuliah hanya akan dibebankan kepada satu dosen. Keuntungan lainnya dari penggunaan metode hungarian dalam model penugasan dosen ini juga karena menggunakan preferensi dari dosen-dosen calon pengampu mata kuliah sebagai alat ukurnya. Setiap dosen akan mengampu mata kuliah sesuai dengan preferensi terbaiknya dengan harapan dosen lebih menguasai mata kuliah yang akan diampunya.

Keywords: Dosen, Masalah Penugasan, Mata Kuliah, Metode Hungarian, Preferensi

Diserahkan: 24-04-2020; Diterima: 18-06-2020; Doi: https://doi.org/10.29303/emj.v3i2.63

\section{Pendahuluan}

Dalam menjalankan pekerjaan sehari-hari, setiap manusia tidak akan terlepas dari adanya penugasan. Sebagai seorang atasan, penugasan kepada bawahan harus dilakukan denganbaik, seksama, dan bijaksana. Atasan harus dapat meletakkan tugas dan tanggung jawab kepada orang atau sumber dayayang tepat di tempat yang tepat (the right man in the rightplace). Dengan demikian, masalah yang terkait dengan manajemen sumber daya dapat dieliminasi dan hasil dengan kualitas yang optimal akan lebih mudah dicapai (Pratama dan Yudoko, 2013).

Dalam suatu kegiatan perkuliahan, salah satu hal pertama yang perlu diperhatikan adalah penjadwalan. Penyusunan jadwal tentu tidak dapat dilakukan sembarangan, karena keberhasilan kegiatan perkuliahan yang efektif ditentukan oleh proses penjadwalan yang optimal. Dalam penyusunan jadwal, hal mutlak yang harus dilakukan adalah pembagian tugas mengajar para dosen sesuai dengan bidang yang mereka tekuni dan mereka inginkan sebab mata kuliah yang sesuai dengan kemampuan dosen akan memerlukan nilai cost yanglebih sedikit dibandingkan dengan yang tidaksesuai (Taha, 2007). Seringkali proses pembagian tugas/penugasan ini memakan waktu yang tidak sebentar dikarenakan prosesnya yang rumit, mengingat banyaknya dosen, mata kuliah, dan ruang kuliah yang tersedia.

Model penugasan (assignment model) merupakan salah satu kasus dari model pemrograman linier (linear programming). Karakteristik khusus yang terdapat pada model khusus ini diantaranya ialah cenderung membutuhkan pembatas (constrains) dan variabel yang sangat banyak sehingga penggunaan komputer dalam penyelesaiannya dengan model matematis (misalnya dengan metode simplex) akan sangat mahal atau proses perhitungannya sangat panjang dan tidak praktis. Masalah akan bertambah jika ada 
pembatas khusus yang sulit dibuat model matematikanya (Taha, 1993).

Assignment problem adalah suatu masalah mengenai pengaturan pada Individu (objek) untuk melaksanakan tugas (kegiatan) sehinggga dapat mengoptimalkan kegiatan penugasan yang akan dilakukan. Untuk meneyelesaikan Assisgnment problem ini digunakan algoritma Metode Hungarian. Metode Hungarian dapat direpresentasikan dengan dua macam cara, yaitu dengan graf bipartit dan matriks. Representasi dengan graf bipartit biasanya digunakan untuk proses maksimasi, seabaliknya representasi dengan matriks digunakan untuk proses minimasi (Dian Perdhana Putra: 2013).

\section{Di Program Studi Matematika FMIPA} Universitas Mataram penulis melakukan studi penugasan dosen dalam mengajar mata kuliah yang menjadi prioritas dosen itu sendiri berdasarkan preferensi tiap dosen. Jika dilakukan penggolongan antara Dosen dan Mata kuliah menjadi dua himpunan yang berhubungan, dan nilai bobot mata kuliah prioritas dosen sebagai relasi penghubung antara dosen dan mata kuliah maka, masalah ini dapat dibawa ke dalam model penugasan dan diselesaikan dengan Metode Hungarian. Kami membatasi permasalahan dengan hanya memilih mata kuliah wajib program studi matematika semester ganjil. Diharapkan dengan dilakukannya penelitian menggunakan metode ini dapat menjadikan bahan acuan dalam penugasan dosen di fakultas pada umumnya.
Pemrograman linear (linear programming) merupakan bagian dari matematika terapan yang dapat dijadikan pertimbangan untuk pengambilan keputusan. Program linear merupakan suatu model yang dapat digunakan untuk pemecahan masalah pengalokasian sumber- sumber yang terbatas secara optimal. Salah satu bagian dari program linear yang dapat dijumpai dalam kehidupan sekitar adalah masalah penugasan (assignment problem). Masalah umum penugasan meliputi $n$ tugas yang harus ditetapkan kepada $m$ pekerja, dimana setiap pekerja memiliki kompetensi yang berbeda dalam menyelesaikan setiap tugas.Pada penelitian ini diterapkan kasus penugasan dosen dalam mengampu mata kuliah di program studi Matematika Fakultas MIPA Universitas Mataram.

\section{Landasan Teori}

\subsection{Teknik Riset Operasi}

Riset operasional (lebih dikenal dengan operation research atau quantitative analysis) merupakan serangkaian kegiatan analisis dan pemodelan matematik untuk keperluan pengambilan keputusan. Banyak persoalan manajerial disuatu organisasi/perusahaan yang senantiasa dikaitkan dengan proses pengambilan keputusan (decision making). Teknik riset operasi ini dipelajari oleh mahasiswa jurusan teknik informatika, teknik mesin, teknik industri, manajemen dan lainnya (Noer, 2010). 


\subsection{Riset Operasional}

Riset operasinal adalah suatu metode ilmiah yang memungkinkan para menejer mengambil keputusan mengenai kegiatan yang ditangani secara kuantitatif (Morse dan Kimball, 2009). Riset operasi merupakan aplikasi metode-metode, teknik-teknik dan peralatan ilmiah dalam menghadapi masalah-masalah yang timbul dalam operasi perusahaan dengan tujuan pemecahan yang optimal.

\subsection{Masalah Penugasan}

Pada model penugasan terdapat sejumlah $m$ sumber ditugaskan kepada sejumlah $n$ tujuan (satu sumber untuk satu tujuan) sedemikian sehingga didapat ongkos total minimum. Biasanya yang dimaksud dengan sumber ialah pekerjaan (atau pekerja), sedangkan yang dimaksud dengan tujuan ialah mesin-mesin (dalam masalah pendidikan pekerja adalah dosen dan mesin adalah matakuliah). Jadi terdapat $m$ pekerjaan yang ditugaskan kepada $n$ mesin yang apabila pekerjaan $i(i=1,2,3, \ldots, \mathrm{m})$ ditugaskan kepada mesin $j(j$ $=1,2,3, \ldots, n)$ akan muncul ongkos penugasan $C_{i j}$. Karena satu pekerjaan ditugaskan hanya pada satu mesin, maka supply yang dapat digunakan pada setiap sumber adalah 1 (atau $a_{i}=$ 1, untuk seluruh $i$ ). Demikian pula halnya dengan mesin-mesin; karena satu mesin hanya dapat menerima satu pekerjaan, maka demand dari setiap tujuan adalah 1 (atau $b_{j}=1$, untuk seluruh $j$ ). Jika ada suatu pekerjaan yang tidak dapat ditugaskan pada mesin tertentu, maka $C_{i j}$ yang berkorespondensi dengannya dinyatakan sebagai $M$ yang merupakan ongkos yang sangat tinggi (Taha, 1993).

Penggambaran umum persoalan penugasan adalah sebagai berikut

\begin{tabular}{c|cccc|}
\multicolumn{1}{c}{} & \multicolumn{4}{c}{ Mesin } \\
\cline { 2 - 5 } Pekerja & 1 & 2 & $\ldots$ & $n$ \\
\cline { 2 - 5 } 2 & $C_{11}$ & $C_{12}$ & $\ldots$ & $C_{1 n}$ \\
$\ldots$ & $C_{21}$ & $C_{22}$ & $\ldots$ & $C_{1 n}$ \\
$M$ & $\ldots$ & $\ldots$ & $\ldots$ & $\ldots$ \\
$C_{m 1}$ & $C_{m 1}$ & $\ldots$ & $C_{m n}$ \\
\cline { 2 - 5 }
\end{tabular}

Secara matematis, model penugasan dapat dinyatakan sebagai berikut:

$X i j=\left\{\begin{array}{c}0, \quad \text { jika pekerjake }- \text { itidak ditugaskan } \\ \text { padamesinke }-j \\ 1, \quad \text { jikapekerjake }-i \text { ditugaskan } \\ \text { padamesinke }-j\end{array}\right.$

Dengan demikian, model persoalan penugasan ini adalah :

$$
\text { Minimumkan } Z=\sum_{i=1}^{n} \sum_{j=1}^{m} C i j X i j
$$

Berdasarkan pembatas

$$
\begin{aligned}
& \sum_{j=1}^{m} X i j=1, i=1,2, \ldots ., n \\
& \sum_{i=1}^{n} X i j=1, j=1,2, \ldots, m
\end{aligned}
$$

\subsection{Metode Hungarian}

Metode hungarian adalah metode yang memodifikasi baris dan kolom dalam matriks efektifitas sampai muncul sebuah komponen nol 
tunggal dalam setiap baris atau kolom yang dapat dipilih sebagai alokasi penugasan. Semua alokasi penugasan yang dibuat adalah alokasi yang optimal dan saat diterapkan pada matriks efektifitas awal, maka akan memberikan hasil penugasan yang paling minimum (Prawisentono, 2011).

Metode hungarian memiliki rumus

$$
\text { Minimumkan } Z=\sum_{i=1}^{n} \sum_{j=1}^{m} C i j X i j
$$

Dengan kendala

$$
\begin{aligned}
& \sum_{j=1}^{m} X i j=1, i=1,2, \ldots ., n \\
& \sum_{i=1}^{n} X i j=1, j=1,2, \ldots, m
\end{aligned}
$$

Dimana :

- $Z$ = Fungsi Tujuan;

- $\quad C i j=$ Nilai kontribusi objek $i$ terhadap tugas $j$;

- $m=$ Jumlah objek (individu atau sumber daya)

- $n=$ Jumlah tugas/pekerjaan yang akan diselesaikan

- $\quad i=$ Subjek pelaku pekerjaan;

- $j=$ Objek yang dikerjakan;

- $X i j=$ Pekerjaan yang akan dilakukan.

Metode hungarian dilakukan dengan syarat :

i. Jumlah $i$ harus sama dengan jumlah $j$;

ii. Setiap sumber harus mengerjakan satu tugas;

iii. Apabila jumlah sumber tidak sama dengan jumlah tugas atau sebaliknya, maka ditambahkan variabel dummy woker atau dummy job.

Proses perhitungan metode hungarian :

1. Lakukan operasi baris, yaitu dengan mengurangkan semua nilai pada baris dengan nilai terbesarnya (operasi perbaris untuk mendapatkan nilai 0 pada tiap barisnya).

2. Lakukan operasi kolom untuk memastikan bahwa pada tiap kolom ada nilai 0 (lakukan pengurangan terhadap nilai terbesar hanya pada kolom yang tidak memiliki nilai 0 ).

3. Lakukan penugasan terbaiknya (merujuk kepada elemen-elemen yang bernilai 0 atau terbesar, dipilih dan dipilah sendiri), dengan cara : (a) Penugasan pertama kali pada baris dan kolom yang memiliki satusatunya nilai 0 . (b) Penugasan berikutnya pada baris saja atau kolom saja yang memiliki satusatunya nilai 0 . (c) Kerjakan terus hingga selesai dan diperoleh nilai terbesar (Ndruru dkk., 2017).

\section{Metode Penelitian}

Penelitian ini merupakan salah satu penerapan riset operasi yang memanfaatkan model penugasan. Penelitian ini menggunakan metode Action Research, yaitu penelitian yang mengembangan metode kerja yang efisien. Dalam penelitian ini setiap dosen diberikan kuesioner 
berisikan pilihan mata kuliah wajib semester ganjil untuk diberikan bobot prioritas berdasarkan preferensi masing-masing dosen. Selanjutnya data yang diperoleh akan diselesaikan dengan menggunakan metode Hungarian. Selain metode Action Research, penelitian ini juga menggunakan metode Library Research, yaitu mencari sumbersumber bacaan dan dipelajari sebagai acuan dalam penulisan artikel. Adapun langkahlangkah penelitian ini adalah : Pertama, menyederhanakan data hasil kuesioner dalam bentuk matriks penugasan dengan urutan prioritas sebagai entry matriks. Kedua, melakukan operasi baris yaitu menentukan nilai terkecil dari setiap baris, kemudian mengurangkan setiap baris dengan nilai terkecil masing-masing baris. Ketiga, melakukan operasi kolom yaitu memeriksa apakah setiap kolom telah mempunyai nilai nol. Jika sudah lanjut ke langkah keempat, tapi jika belum kurangkan setiap kolom yang belum memiliki elemen nol dengan nilai terkecil masing-masing kolom tersebut. Keempat, menarik garis seminimal mungkin yang harus mengenai angka nol pada setiap baris dan kolom. Kemudian kurangi semua elemen yang tidak tertutup garis dengan elemen terkecil dan elemen yang dua kali kena garis ditambahkan dengan elemen terkecil. Kelima, jika semua baris dan kolom yang mempunyai nilai nol sudah tertutup garis, maka tabel sudah optimal, jika belum ulangi langkah keempat sampai menghasilkan solusi optimal.

\section{Hasil Dan Pembahasan}

Penelitian ini dilakukan di program studi Matematika Fakultas MIPA, Universitas
Mataram. Pada permasalahan ini kami menentukan bahwa ada 13 dosen dan 13 Mata kuliah wajib di program studi Matematika Fakultas MIPA, Universitas Mataram. Disini ditentukan dosen sebagai Pekerja, mata kuliah sebagai Mesin dan Preferensi Prioritas Dosen terhadap kemampuan mengangpu mata kuliah dengan bobot 1 sampai 13 sebagai biaya. Untuk memudahkan pemberian indeks kita misalkan mata kuliah Matematika Dasar $=$ M1, Statistika Dasar $=$ M2, Geometri Analaitik $=$ M3, Kalkulus Lanjur $=$ M4, Logika dan Himpunan $=$ M5, ALE $=$ M6, Program Linear $=$ M7, Algoritma dan Pemrograman $=$ M8, Analisis Real II = M9, Metoe Numerik $=$ M10, PDP $=$ M11, Statistika Matematika $=$ M12, Seminar $=$ M13 dan Doen 1 = D1, Doen 2= D2, Dosen $3=\mathrm{D} 3$, Dosen $4=\mathrm{D} 4$, Dosen $5=\mathrm{D}$, Dosen $6=\mathrm{D} 6$, Dosen $7=\mathrm{D} 7$, Dosen $8=\mathrm{D} 8$, Dosen $9=\mathrm{D} 9$, Dosen $10=\mathrm{D} 10$, Dosen $11=$ D11, Doseen $12=$ D12, Dosen $13=$ D13. Berdasarkan data yang diperoleh dari hasil kuesioner dibentuk matriks penugasan seperti pada Tabel 1.1.

Tabel 1.1. Hasil Kuesioner tentang pereferensi dosen dalam mengampu mata kuliah di Fakultas MIPA, Universitas Mataram.

\begin{tabular}{|c|c|c|c|c|c|c|c|c|c|c|c|c|c|}
\hline \multirow{2}{*}{ DOSEN } & \multicolumn{13}{|c|}{ MATA KULIAH } \\
\hline & Ml & M2 & м3 & M4 & Ms & M6 & M7 & M8 & м9 & м10 & M11 & M12 & M13 \\
\hline D1 & 3 & 9 & 10 & 4 & 1 & 7 & 6 & 12 & 2 & 5 & 11 & 13 & 8 \\
\hline D2 & 2 & 1 & 13 & 5 & 3 & 7 & 8 & 9 & 10 & 11 & 12 & 4 & 6 \\
\hline D3 & 3 & 6 & 2 & 5 & 4 & 7 & 8 & 13 & 1 & 10 & 12 & 11 & 9 \\
\hline D4 & 3 & 11 & 13 & 7 & 4 & 1 & 6 & 12 & 2 & 10 & 9 & 5 & 8 \\
\hline D5 & 3 & 12 & 5 & 6 & 11 & 4 & 10 & 2 & 7 & 1 & 8 & 13 & 9 \\
\hline D6 & 4 & 1 & 11 & 8 & 5 & 7 & 6 & 10 & 13 & 9 & 12 & 2 & 3 \\
\hline D7 & 4 & 12 & 5 & 7 & 1 & 2 & 3 & 6 & 8 & 9 & 10 & 13 & 11 \\
\hline D8 & 1 & 6 & 12 & 4 & 8 & 10 & 3 & 9 & 13 & 5 & 2 & 11 & 7 \\
\hline D9 & 1 & 4 & 3 & 5 & 6 & 7 & 10 & 12 & 2 & 11 & 8 & 9 & 13 \\
\hline
\end{tabular}




\begin{tabular}{|l|l|l|l|l|l|l|l|l|l|l|l|l|l|} 
D10 & 8 & 13 & 5 & 7 & 10 & 1 & 6 & 2 & 3 & 4 & 9 & 12 & 11 \\
\hline D11 & 2 & 1 & 8 & 4 & 6 & 7 & 5 & 13 & 10 & 9 & 11 & 3 & 12 \\
\hline D12 & 2 & 12 & 5 & 1 & 7 & 10 & 9 & 13 & 3 & 8 & 4 & 11 & 6 \\
\hline D13 & 5 & 6 & 2 & 10 & 4 & 1 & 3 & 13 & 9 & 7 & 8 & 11 & 12 \\
\hline
\end{tabular}

Pada tabel 1.1 dapat kita rumuskan suatu model sebagai berikut:

$\operatorname{Min} f=\sum_{j=1}^{13} \sum_{i=1}^{13} C_{D_{i} M_{j}} \cdot x_{D_{i} M_{j}}$

Dengan kendala :

$\sum_{j=1}^{13} x_{D_{1} M_{j}}=1$, $\sum_{j=1}^{13} x_{D_{2} M_{j}}=1$, $\sum_{j=1}^{13} x_{D_{3} M_{j}}=1$, $\sum_{j=1}^{13} x_{D_{4} M_{j}}=1$,

$\sum_{j=1}^{13} x_{D_{5} M_{j}}=1$, $\sum_{j=1}^{13} x_{D_{6} M_{j}}=1$, $\sum_{j=1}^{13} x_{D_{7} M_{j}}=1$, $\sum_{j=1}^{13} x_{D_{8} M_{j}}=1$, $\sum_{j=1}^{13} x_{D_{9} M_{j}}=1$, $\sum_{j=1}^{13} x_{D_{10} M_{j}}=1$, $\sum_{j=1}^{13} x_{D_{11} M_{j}}=1$, $\sum_{j=1}^{13} x_{D_{12} M_{j}}=1$, $\sum_{j=1}^{13} x_{D_{13} M_{j}}=1$, $\sum_{i=1}^{13} x_{D_{i} M_{1}}=1$,

$\sum_{i=1}^{13} x_{D_{i} M_{2}}=1$, $\sum_{i=1}^{13} x_{D_{i} M_{3}}=1$, $\sum_{i=1}^{13} x_{D_{i} M_{4}}=1$, $\sum_{i=1}^{13} x_{D_{i} M_{5}}=1$, $\sum_{i=1}^{13} x_{D_{i} M_{6}}=1$, $\sum_{i=1}^{13} x_{D_{i} M_{7}}=1$, $\sum_{i=1}^{13} x_{D_{i} M_{8}}=1$, $\sum_{i=1}^{13} x_{D_{i} M_{9}}=1$,

$\sum_{i=1}^{13} x_{D_{i} M_{10}}=1$, $\sum_{i=1}^{13} x_{D_{i} M_{11}}=1$, $\sum_{i=1}^{13} x_{D_{i} M_{12}}=1, \quad \sum_{i=1}^{13} x_{D_{i} M_{13}}=1$,

$\sum_{j=1}^{13} \sum_{i=1}^{13} x_{D_{i} M_{j}}>0$

\section{Dengan :}

$C_{D_{i} M_{j}}$ :biaya (pereferensi) Dosen ke-i dengan mata kuliah ke-j.

$x_{D_{i} M_{j}} \quad$ :pekerja (dosen) ke-i yang mengerjakan (mengampu) mesin (mata kuliah) ke-j
Adapun langkah-langkah penyeleaian masalah penugasan diatas dengan metode Hungarian:

Langkah pertama setiap garis pada matriks di tabel 1.1 dikurangi dengan elemen terkecilnya yaitu 1. Sehingga diperoleh matrik baru yaitu seperti pada tabel 1.2.

Tabel 1.2. Hasil langkah 1 dengan metode Hungarian.

\begin{tabular}{|l|l|l|l|l|l|l|l|l|l|l|l|l|l|}
\hline \multirow{2}{*}{ DOSEN } & \multicolumn{2}{|l|}{ MATA KULIAH } \\
\cline { 2 - 15 } & M1 & M2 & M3 & M4 & M5 & M6 & M7 & M8 & M9 & M10 & M11 & M12 & M13 \\
\hline D1 & 2 & 8 & 9 & 3 & 0 & 6 & 5 & 11 & 1 & 4 & 10 & 12 & 7 \\
\hline D2 & 1 & 0 & 12 & 4 & 2 & 6 & 7 & 8 & 9 & 10 & 11 & 3 & 5 \\
\hline D3 & 2 & 5 & 1 & 4 & 3 & 6 & 7 & 12 & 0 & 9 & 11 & 10 & 8 \\
\hline D4 & 2 & 10 & 12 & 6 & 3 & 0 & 5 & 11 & 1 & 9 & 8 & 4 & 7 \\
\hline D5 & 2 & 11 & 4 & 5 & 10 & 3 & 9 & 1 & 6 & 0 & 7 & 12 & 8 \\
\hline D6 & 3 & 0 & 10 & 7 & 4 & 6 & 5 & 9 & 12 & 8 & 11 & 1 & 2 \\
\hline D7 & 3 & 11 & 4 & 6 & 0 & 1 & 2 & 5 & 7 & 8 & 9 & 12 & 10 \\
\hline D8 & 0 & 5 & 11 & 3 & 7 & 9 & 2 & 8 & 12 & 4 & 1 & 10 & 6 \\
\hline D9 & 0 & 3 & 2 & 4 & 5 & 6 & 9 & 11 & 1 & 10 & 7 & 8 & 12 \\
\hline D10 & 7 & 12 & 4 & 6 & 9 & 0 & 5 & 1 & 2 & 3 & 8 & 11 & 10 \\
\hline D11 & 1 & 0 & 7 & 3 & 5 & 6 & 4 & 12 & 9 & 8 & 10 & 2 & 11 \\
\hline D12 & 1 & 11 & 4 & 0 & 6 & 9 & 8 & 12 & 2 & 7 & 3 & 10 & 5 \\
\hline D13 & 4 & 5 & 1 & 9 & 3 & 0 & 2 & 12 & 8 & 6 & 7 & 10 & 11 \\
\hline
\end{tabular}

Pada tabel 1.2 masih terlihat ada beberapa kolom yang belum mempunyai angka 0 (berwarna hijau). Oleh karena itu, setiap kolom tersebut dikurangi lagi dengan elemen terkecil dimasing-masing kolom sampai setiap baris dan kolom mempunyai angka 0. Maka akan diperoleh solusi awal seperti pada tabel 1.3. berikut:

Tabel 1.3. Solusi awal dengan metode Hungarian.

\begin{tabular}{|c|c|c|c|c|c|c|c|c|c|c|c|c|c|}
\hline \multirow{2}{*}{ DOSEN } & \multicolumn{13}{|c|}{ MATA KULIAH } \\
\hline & $\mathrm{Ml}$ & M2 & M3 & M4 & M5 & м6 & M7 & M8 & M9 & м10 & M11 & M12 & M13 \\
\hline D1 & 2 & 8 & 8 & 3 & 0 & 6 & 3 & 10 & 1 & 4 & 9 & 11 & 5 \\
\hline D2 & 1 & 0 & 11 & 4 & 2 & 6 & 5 & 7 & 9 & 10 & 10 & 2 & 3 \\
\hline D3 & 2 & 5 & 0 & 4 & 3 & 6 & 5 & 11 & 0 & 9 & 10 & 9 & 6 \\
\hline D4 & 2 & 10 & 11 & 6 & 3 & 0 & 3 & 10 & 1 & 9 & 7 & 3 & 5 \\
\hline
\end{tabular}




\begin{tabular}{|l|l|l|l|l|l|l|l|l|l|l|l|l|l|} 
D5 & 2 & 11 & 3 & 5 & 10 & 3 & 7 & 0 & 6 & 0 & 6 & 11 & 6 \\
\hline D6 & 3 & 0 & 9 & 7 & 4 & 6 & 3 & 8 & 12 & 8 & 10 & 0 & 0 \\
\hline D7 & 3 & 11 & 3 & 6 & 0 & 1 & 0 & 4 & 7 & 8 & 8 & 11 & 8 \\
\hline D8 & 0 & 5 & 10 & 3 & 7 & 9 & 0 & 7 & 12 & 4 & 0 & 9 & 4 \\
\hline D9 & 0 & 3 & 1 & 4 & 5 & 6 & 7 & 10 & 1 & 10 & 6 & 7 & 10 \\
\hline D10 & 7 & 12 & 3 & 6 & 9 & 0 & 3 & 0 & 2 & 3 & 7 & 10 & 8 \\
\hline D11 & 1 & 0 & 6 & 3 & 5 & 6 & 2 & 11 & 9 & 8 & 9 & 1 & 9 \\
\hline D12 & 1 & 11 & 3 & 0 & 6 & 9 & 6 & 11 & 2 & 7 & 2 & 9 & 3 \\
\hline D13 & 4 & 5 & 0 & 9 & 3 & 0 & 0 & 11 & 8 & 6 & 6 & 9 & 9 \\
\hline
\end{tabular}

Setelah memperoleh solusi awal seperti pada tabel 1.3, selanjutnya akan dilakukan penarikan garis yang melewati semua nol dengan cara memilih baris atau kolom yang mempunyai nol paling banyak terlebih dahulu. Hal ini dilakukan agar garis yang terbentuk bisa seminimal mungkin. Setelah menarik garis elanjutnya untuk elemen yang tidak terkena garis dikurangi dengan elemen terkecil yang tidak terkena garis, sedangkan untuk yang kena garis dua kali ditambahkan dengan 1. Maka akan didapatkan solusi optimal dengan metode Hungarian seperti pada tabel 1.4 berikut:

Tabel 1.4. Solusi optimal menggunakan metode Hungarian.

\begin{tabular}{|c|c|c|c|c|c|c|c|c|c|c|c|c|c|}
\hline \multirow{2}{*}{$\begin{array}{l}\text { DOSE } \\
\mathrm{N}\end{array}$} & \multicolumn{13}{|c|}{ MATA KULIAH } \\
\hline & $\stackrel{M}{1}$ & $\begin{array}{l}\mathrm{M} \\
2\end{array}$ & ${ }_{3}^{\mathrm{M}}$ & ${ }_{4}^{\mathrm{M}}$ & $\underset{5}{\mathrm{M}}$ & $\begin{array}{l}\mathrm{M} \\
6\end{array}$ & $\frac{M}{7}$ & $\begin{array}{l}\mathrm{M} \\
8\end{array}$ & $\begin{array}{c}\mathrm{M} \\
9\end{array}$ & $\begin{array}{l}\text { M1 } \\
0\end{array}$ & $\begin{array}{l}\text { M1 } \\
1\end{array}$ & $\begin{array}{l}\mathrm{M} 1 \\
2\end{array}$ & $\begin{array}{l}\mathrm{M} 1 \\
3\end{array}$ \\
\hline D1 & 2 & 8 & 7 & 3 & 0 & 6 & 3 & $\begin{array}{l}1 \\
0\end{array}$ & 0 & 4 & 8 & 10 & 4 \\
\hline D2 & 1 & 0 & $\begin{array}{l}1 \\
0\end{array}$ & 4 & 2 & 6 & 5 & 7 & 8 & 10 & 9 & 1 & 2 \\
\hline D3 & 3 & 6 & 0 & 5 & 4 & 7 & 6 & $\begin{array}{l}1 \\
2\end{array}$ & 0 & 10 & 10 & 9 & 6 \\
\hline D4 & 2 & $\begin{array}{l}1 \\
0\end{array}$ & $\begin{array}{l}1 \\
0\end{array}$ & 6 & 3 & 0 & 3 & $\begin{array}{l}1 \\
0\end{array}$ & 0 & 9 & 6 & 2 & 4 \\
\hline D5 & 2 & $\begin{array}{l}1 \\
1\end{array}$ & 2 & 5 & $\begin{array}{l}1 \\
0\end{array}$ & 3 & 7 & 0 & 5 & 0 & 5 & 10 & 5 \\
\hline D6 & 3 & 1 & 9 & 8 & 5 & 7 & 4 & 9 & $\begin{array}{l}1 \\
2\end{array}$ & 9 & 10 & 0 & 0 \\
\hline D7 & 3 & $\begin{array}{l}1 \\
1 \\
\end{array}$ & 2 & 6 & 0 & 1 & 0 & 4 & 6 & 8 & 7 & 10 & 7 \\
\hline D8 & 1 & 6 & $\begin{array}{l}1 \\
0 \\
\end{array}$ & 4 & 8 & $\begin{array}{l}1 \\
0 \\
\end{array}$ & 1 & 8 & $\begin{array}{l}1 \\
2 \\
\end{array}$ & 5 & 0 & 9 & 4 \\
\hline D9 & 0 & 3 & 0 & 4 & 5 & 6 & 7 & $\begin{array}{l}1 \\
0\end{array}$ & 0 & 10 & 5 & 6 & 9 \\
\hline D10 & 7 & $\begin{array}{l}1 \\
2\end{array}$ & 2 & 6 & 9 & 0 & 3 & 0 & 1 & 3 & 6 & 9 & 7 \\
\hline D11 & 1 & 0 & 5 & 3 & 5 & 6 & 2 & $\begin{array}{l}1 \\
1\end{array}$ & 8 & 8 & 8 & 0 & 8 \\
\hline D12 & 1 & $\begin{array}{l}1 \\
1\end{array}$ & 2 & 0 & 6 & 9 & 6 & $\begin{array}{l}1 \\
1\end{array}$ & 1 & 7 & 1 & 8 & 2 \\
\hline D13 & 5 & 6 & n & $\begin{array}{l}1 \\
0\end{array}$ & 4 & 1 & 1 & $\begin{array}{l}1 \\
2\end{array}$ & 8 & 6 & 6 & 9 & 9 \\
\hline
\end{tabular}

$\operatorname{Min} f=\sum_{j=1}^{13} \sum_{i=1}^{13} C_{D_{i} M_{j}} \cdot x_{D_{i} M_{j}}$

$$
\begin{aligned}
= & x_{D_{9} M_{1}}+x_{D_{2} M_{2}}+x_{D_{13} M_{3}}+x_{D_{12} M_{4}+} \\
& x_{D_{1} M_{5}}+x_{D_{4} M_{6}}+x_{D_{7} M_{7}}+x_{D_{10} M_{8}}+ \\
& x_{D_{3} M_{9}}+x_{D_{5} M_{10}}+x_{D_{8} M_{11}}+x_{D_{11} M_{12}}+ \\
& x_{6 M_{13}} \\
= & 1+1+2+1+1+1+3+2+ \\
& 1+1+2+3+3 \\
= & 22
\end{aligned}
$$

Untuk melihat adanya banyak solusi, penulis menggunakan bantuan Research Operation Calculator untuk menyelesaikan masalah penugasan tersebut. Adapun hasil yang diperoleh sama dan mempunyai solusi tunggal. Adapaun hasilnya yaitu seperti pada Gambar 1.1 dan Gambar 1.2 berikut:

Gambar 1.1. pengimputan data pada Research Operation Calculator menggunakan Metode Hungarian.

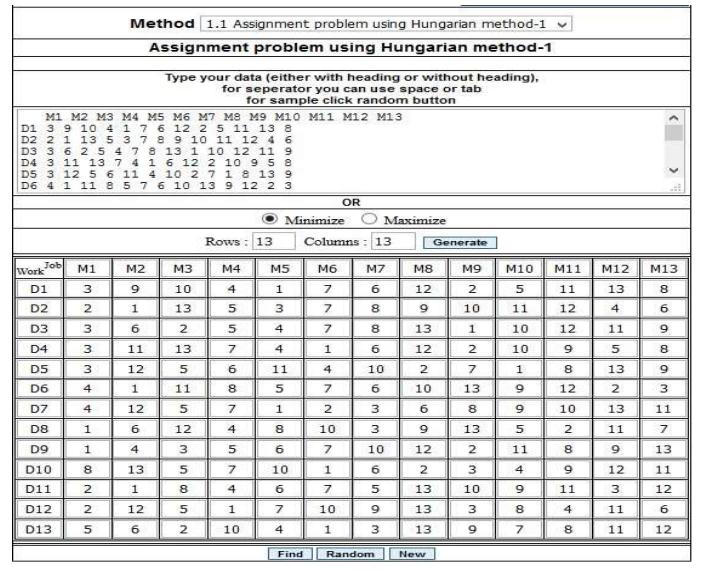

Gambar 1.2. Hasil optimal dengan Research Operation Calculator menggunakan Metode Hungarian. 


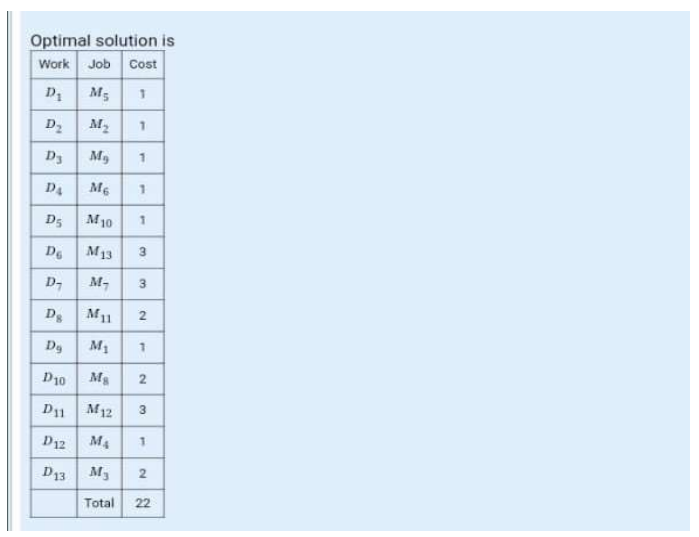

\section{Penutup}

\section{Kesimpulan}

Berdasarkan hasil penelitian ini dapat disimpulkan bahwa penerapan metode Hungarian dapat digunakan untuk menentukan penugasan dosen dalam mengampu mata kuliah di program studi Matematika Fakultas MIPA, Universitas Mataram. Adapun hasil yang diperoleh dalam menentukan preferensi dosen dalam mengampu mata kuliah di program studi Matematika Fakultas MIPA, Universitas Mataram adalah seperti pada tabel 1.5 berikut:

Tabel 1.5. hasil preferensi dosen dalam mengampu mata kuliah.

\begin{tabular}{|l|l|}
\hline DOSEN & Mata Kuliah Yang diampu \\
\hline DOSEN 1 & Logaritma dan Himpunan \\
\hline DOSEN 2 & Statistika Dasar \\
\hline DOSEN 3 & Analisis Real II \\
\hline DOSEN 4 & Aljabar Linear Elementer \\
\hline DOSEN 5 & Metode Numerik \\
\hline DOSEN 6 & Seminar \\
\hline DOSEN 7 & Program linear \\
\hline DOSEN 8 & Persamaan Diferensial Parsial \\
\hline
\end{tabular}

\begin{tabular}{|l|l|} 
DOSEN 9 & Matematika Dasar \\
\hline DOSEN 10 & Algoritma dan Pemrograman \\
\hline DOSEN 11 & Statistika Matematika \\
\hline DOSEN 12 & Kalkulus Lanjut \\
\hline DOSEN 13 & Geometri Analitik \\
\hline
\end{tabular}

\section{Saran}

Adapun saran dari penulis berdasarkan hasil penelitian adalah sebagai berikut;

1. Ditujukan kepada Fakultas, yakni sebagai masukan untuk dijadikan syarat dalam penentuan dosen pengampuh mata kuliah berdasarkan preferensi setiap dosen.

2. Ditujukan kepada pelajar/mahasiswa, yakni metode Hungarian sangat tepat digunakan sebagai solusi dalam menyelesaikan permasalahan yang berkaitan dengan penugasan.

\section{DAFTAR PUSTAKA}

Anton, $\mathrm{H}$ dan Rorres, C.W. Aljabar Linear Elementer Versi Aplikasi. Edisi ke-8 [Indriasari, R. Alih bahasa].Safitri, A.(ed), Jakarta: Erlangga ; 2004.

Bustanul Arifin noer, (2010), Riset Operasional,Yogyakarta.

Hillier, S.F. dan Lieberman. Introduction To Operations Research, Eighth Edition, New York: Mc Graw-Hill ; 2004.

Jackson, M. C. (1982). The nature of soft systems thinking: The work of Churchman, Ackoff and Checkland. Journal of applied systems analysis, 9(1), 17-29.

Morse, P. M., Kimball, G. E., \& Gass, S. I. (2003). Methods of operations research. Courier Corporation.

Ndruru, E., Waruwu, F. T., \& Yanny, A. (2017). Alokasi Pekerja Pada Suatu Proyek Dengan Metode Hungarian 
(Studi Kasus: Pt. Ira Widya Utama Medan). KOMIK (Konferensi Nasional Teknologi Informasi dan Komputer), 1(1).

Pratama, A.N. \& Yudoko, G, "Proposal for Supplier Relationship Management at PT XL Axiata Tbk.", The Indonesian Journal of Business administration, Vol. 2, No. 17, 2013.

Putra Dian Perdhana.2013. Penerapan Hungarian Method Untuk Menyelesaikan Personnel Assignmenet problem. Bandung: Artikel Teknik Informatika.

Taha, H. A., 2007. Operations Research: An Introduction 8th Edition. Pearson Prentice Hall. Pearson Education, Inc.

Taha, Hamdy A., (1993). Operations Research: An Introduction. Edisi ketiga. Macmillan Publishing Co, New York. 